\title{
"Aerosol"-A Prospective Contaminant of Dental Environment!
}

\author{
Yogeshwari Swaminathan ${ }^{1}$, Julie Toby Thomas ${ }^{2}$ \\ ${ }^{\prime}$ (Intern (BDS), Saveetha Dental College \& Hospital, Chennai, India) \\ 2 (MDS, Department of Periodontics, Saveetha Dental College \& Hospital, Chennai, India)
}

\begin{abstract}
Dental aerosols are produced in a wide range during the dental procedure. Air-water aerosol produced during dental treatment emerges from patient's mouth and mixes with the air in the surrounding, causing a change in its composition. This can result in contaminated environment which can be hazardous to the dentist as well as to the patient. Many methods can be undertaken to avoid the potential ill effects caused by the dental aerosol.
\end{abstract}

Keywords: Aerosol, splatter, chlorhexidine, herbal mouth wash, dental unit water line,

\section{Introduction}

Dentist, dental hygienist and oral health care workers practices in a highly contaminated environment which is the human mouth where they are exposed to variety of bacteria, viruses, fungi and protozoan from many sources [1]. Dental unit being the main unit of dental surgery equipment consist of dental chair, operator chair, a lamp and a spittoon. Every dental unit has a minimum of three working handpieces that is high speed handpiece, low speed handpiece and an air water syringe. The unit is supplied with water through a system of thin plastic tubes which constitutes dental unit water lines.

Apart from that, every chair is equipped with an ultrasonic scaler unit for carrying out oral prophylaxis. All these equipments, when used for various dental procedures can result in the formation of aerosol and splatter which are commonly contaminated with bacteria, virus, fungi and blood. Microorganism which is present in the mouth and respiratory tract can be transported in the aerosol produced during dental procedures leading to respiratory infections, skin infection and other systemic diseases in immunocompromised patient. They also contaminate the mucous membrane of the mouth, respiratory passages, eyes of dental professionals and patients and the surrounding surfaces [3]. The most rigorous aerosol and splatter emission occurs during oral prophylaxis with ultrasonic scaler tips and during the use of bur with high speed handpiece[3].

Hence this article highlights on the reasons and the potential risks that can be encountered with dental aerosols. It also discusses various methods undertaken to control the infection caused by the aerosol.

\section{Definition Of Aerosol And Splatter}

The terminology aerosol and splatter in dental environment were proposed by Micik in their pioneering work on aerobiology [2]. Aerosols are combination of both liquid and solid particles. Majority of the particles in the aerosol are less than 100 microns and when the water gets evaporated, they form 'droplet nuclei' which is composed of saliva, dried serum and microorganisms. The size of the droplet nuclei varies from 0.5 to 10 microns which can reach pulmonary alveoli or float in the air for several hours. They can also penetrate deep into the respiratory system $[3,4,7]$.

The term splatter was defined as airborne particle which are larger than 50 micron in diameter. Splatters are further depicted as a mixture of air, water and / or solid substances which is of 50 microns to several millimeters in diameter and are visible to naked eye. Aerosol and splatter production which occur with usage of ultrasonic scaler tip and burs at a high speed handpiece is considered to be very exhaustive or intensive. They have sufficient mass and kinetic energy to move ballistically and settle on object due to gravitational forces. They have limited penetration into the respiratory system. They can come in contact with mucosa of nostrils, open mouth, eyes, skin as well as on the hair and clothes $[1,2,3,4,5]$.

\section{Sources Of Dental Aerosol Causing Infection}

Sources of dental aerosol produced during dental procedures are from the:

1. Patient

2. Dental unit waterlines (DUWL)

3. Instruments

\section{Patient}

Dental aerosol can be produced from the patients. The amount of contamination of dental aerosol depends on the quality of saliva, nasal and throat secretion, blood, dental plaque, periodontal infection, blood 
and presence of any dental infection [3]. Therefore aerosol composition differs from patient to patient depending on the site and type of the procedure like tooth preparation and oral prophylaxis $[3,8]$.

\section{Dental Unit Waterlines (DUWL)}

The tubing in DUWL is constructed in such a way that, the centre of the lumen has the maximum flow of water and the periphery has the minimal flow. Reasons of contamination of DUWL may be due to narrow bore water lines, water stagnation, heating of dental chair unit, anti retraction valve failure and contamination of reservoir bottles [33]. The bacterial biofilm which forms on the surface of the DUWL tubings are very adherent. This is due to the intermittent usage of the dental unit, improper cleaning and sterilization of the DUWL $[9,10]$.

Another factor which encourages the bacterial adherence to the surface of the tube is the material used to make the tube which is hydrophobic polymeric plastic tubing (eg: polyvinyl chloride and polyurethane) [9]. This leads to the formation of biofilm which releases high number of planktonic organism within 8 hours followed by formation of community of micro colonies which is protected by extracellular amorphous matrix in 6 days $[9,15]$. Microorganisms from the biofilm that shed during the usage of dental units through the DUWL to the oral cavity can lead to spread of infection. A study done by Yabune $\mathrm{T}$ et al in 2005 demonstrated that materials like polyvinylidene fluoride were more effective in biofilm formation than conventional DUWL tubing made of polyurethane [34]. Microoragnisms which are isolated from the dental dental unit water line have been listed in table 1,2 and 3 [9].

TABLE 1 Types of bacteria :

\begin{tabular}{|c|l|l|}
\hline $\begin{array}{c}\text { Achromobacter } \\
\text { xyloxidans }\end{array}$ & Fusobacterium spp & Nocardia spp \\
\hline Acinetobacter spp & Klebsiella pnuemoniae & Pasteurella spp \\
\hline Actinomyces spp & Lactobacillus spp & Proteus vulgaris \\
\hline Alicaligenes dentrificans & Legionella spp & Pseudomonas aeruginosa \\
\hline Bacillus spp & Micrococcus spp & Burkholderia cepacia \\
\hline Bacteriodes spp & Moraxella spp & Streptococcus spp \\
\hline Caulobacter spp & Mycobacterium avium & Staphylococcus spp \\
\hline Flavobacterium spp & Mycobacterium spp & Xanthomonas spp \\
\hline
\end{tabular}

TABLE 2 Types of fungi :

\begin{tabular}{|l|}
\hline Phoma spp \\
\hline Penicillicilim spp \\
\hline Cladosporium spp \\
\hline Alternaria spp \\
\hline Scopulariopsis spp \\
\hline
\end{tabular}

TABLE 3Types of protozoa

\begin{tabular}{|l|}
\hline Acanthomoeba spp \\
\hline Cryptosporidium spp \\
\hline Microsporidium spp \\
\hline Giardia spp \\
\hline
\end{tabular}

\section{Instruments}

Instruments which can produce dental aerosol include:

1. Dental handpieces along with burs

2. Ultrasonic scaler tips

3. Polishing cups

Aerosols produced during dental treatment contain air from the instruments, water from DUWL, patient's saliva and blood. It is also always accompanied by splatter which can be contaminated with bacteria, viruses, fungi and protozoan (9). The most severe aerosol and splatter production occurs during the usage of ultrasonic scaler tips and burs on a high speed handpieces $(1,3)$. A study done by AL Maghloutha et al in 2004 demonstrated that the bacterial contamination in the dental aerosol was decreased by $50-70 \%$ at the end of the working day (12).

\section{Risks To The Dental Surgeons And Patients}

During the dental procedures, the most contaminated area was found to be the doctor's and assistant's masks followed by the dental unit lamp, surfaces close to the spittoons and mobile instrument material table. Among the microorganisms which are isolated from these contaminated surfaces include streptococcus genus 
(42\%), staphylococcus $(41 \%)$ and gram negative bacteria. Microorganism isolated from the environment of dental clinic includes nondiptherial corynebacterium, Staphylococcus aureus $(0.6 \%)$, Pseudomonas spp. $(0.6 \%)$ and fungi $(0.9 \%)[3,16]$.

The oral environment, being a unique environment with moist, proper temperature and contains certain metabolites can favor bacterial growth. Hence the use the personal protection equipment is critical. Study done by Nejabanesh.F et al in 2013 demonstrated that areas around nose and inner corner of the eyes are significantly at a higher rate of contamination [35].

Modern dental chair units consist of a network of interconnected narrow-bore plastic tubes called dental unit water lines. Quality of water delivered through these water lines pose considerable importance due to regular exposure of aerosols during dental procedures. Favourable environment for microbial proliferation and biofilm formation exist in the water pipeline. Contamination with high densities of gram negative microorganism like pseudomonas Aeroginosa and Legionella species have been reported [36].

The microflora from the DUWL and the patient's oral cavity in the form of aerosol mixes with the surrounding air thus leading to change in the original composition of the environment. Eventually it acts as a source of infection for both the dentist as well as the patients. It can also contaminate the nearby instruments on the instrument trays which can further act as a source of infection to the patient. Failure to attain the infection control can affect the dental personnel as well as the patient. The mode of spread of infection is through inhalation, contact with the mucous membrane of the conjunctiva, nose and oral cavity $[3,7]$.

Snophia S et al, in 2011 reported two patients contaminated with Pseudomonas Aerugiosa when treated in a dental clinic, where DUWL was the source of infection. The microorganism which was isolated from the oral abscess developed in these patients was the same strain isolated from the DUWL [4]. Other respiratory infections reported were mild flu and pneumonia, which was caused by legionella pneumophilia, non pneumophilla spp and mycobacterium spp including mycobacterium avium, staphylococcal and streptococcal infection $[9,13,19]$.

Caroline $\mathrm{L}$ et al reported that the presence of Legionella antibodies in dental personnel is higher in comparison to the general population [9]. Immunocompromised individuals like HIV patients can be infected by Mycobacterium avium as well as non tuberculous mycobacterium by inhalation,ingestion or inoculation in oral wounds. Acanthamoeba derived from the biofilm in DUWL is proven to cause amoebic keratitis in dental personnel and patient who wears contact lenses [20]. Staphylococcal infection, viral infection, conjunctivitis and other skin infection also could occur [22].

Among the risks which are fatal includes tuberculosis (TB) and severe acute respiratory syndrome (SARS). Cases reported so far, hypothesized that blood borne pathogens like HIV, HBV, and HCV can be transmitted through the inhalation of blood containing aerosol via the microlesion in the mucosa of the airways which acts as the potential access for such viruses [7,23].

Study done by Pankhurst CL et al, in 2005 demonstrated a temporal association between occupational exposure to contaminated DUWL output water with aerobic bacterial counts of more than $200 \mathrm{CFU} / \mathrm{ml}$ at $37^{\circ} \mathrm{c}$ and development of asthma in a subgroup of dentist following commencement of dental training [37].

\section{Modes Of Prevention}

1. Screening of patients - A thorough case history should be taken as it helps in early diagnosis of the disease before the commencement of any dental procedure [24].

2. Immunization of dental personnel against Hepatitis A [3], Hepatitis B [3,27], Influenza, Mumps, Measles, Tetanus, Rubella, Tuberculosis, whooping cough [24,27], Varicella, MMR, DPT, Rubeola, Meningitis, Polio and Diptheria for infection control should be done at proper periodic intervals [3, 24,27]. Table 4 list the vaccination recommended to be taken by any health professional [32].

TABLE 4List of vaccination recommended [32]

\begin{tabular}{|c|c|}
\hline Vaccines & Recommendations in brief \\
\hline Hepatitis B & $\bullet$ Get the 3-dose series \\
& $\begin{array}{l}1^{\text {st }} \text { dose }: \text { now } \\
2^{\text {nd }} \text { dose: in 1 month, } \\
3^{\text {rd }} \text { dose : approximately } 5 \text { months after the2 nd dose } \\
\bullet \text { Get anti-HBs serologic tested 1-2 months after } 3^{\text {rd }} \text { dose }\end{array}$ \\
\hline Flu (Influenza) & One dose of influence vaccine annually \\
\hline MMR (Measles, & If you don't have an up to date blood test that shows you are immune to measles, mumps, \\
Mumps, \& Rubella) & and rubella, get 2 doses of MMR, 4 weeks apart. \\
\hline
\end{tabular}




\begin{tabular}{|c|c|}
\hline $\begin{array}{c}\text { Varicella } \\
\text { (Chickenpox) }\end{array}$ & $\begin{array}{c}\text { If you don't have an up to date blood test that shows you are immune to varicella , get 2 } \\
\text { doses of varicella vaccine, 4 weeks apart. }\end{array}$ \\
\hline $\begin{array}{c}\text { Tdap (Tetanus, } \\
\text { Diphtheria, Pertussis) }\end{array}$ & $\begin{array}{r}\text { Get a one-time dose of Tdap as soon as possible if you have not received Tdap } \\
\text { previously (regardless of when previous dose of Td was received). } \\
\text { Get Td boosters every 10 years thereafter. } \\
\text { Pregnant HCWs need to get a dose of Tdap during each pregnancy. }\end{array}$ \\
\hline Meningococcal & Those who are routinely exposed to isolates of N. meningitidis should get one dose. \\
\hline
\end{tabular}

3. Personal hygiene [27] and hand hygiene [24] of dental personnel should be maintained.

4. Personal protective equipments to be used during dental treatment are gloves, mouth mask, head cap, face shield, eye protective wear (goggles/ eye wear) and gowns [27].

5. Dental unit waterlines (DUWL)

Approaches in risk reduction for DUWL can be broadly divided into:-

.1.1. Non chemical approach

.1.2. Chemical approach

Non chemical approaches include flushing of DUWL water, improving the quality of water, using anti retraction valves and retrograde aspiration. Use of filters have also been tried but have demonstrated to have no impact. The disadvantage in usage of filters includes clogging of filters due to biofilm deposition and favourable growth of bacteria within 24 hours, hence disposable filters were recommended $[3,9,28]$.

An autoclavable assembly of water reservoir which is made up of silicon multilumen dental unit water line tubing and fittings has been designed to be sterilized between patients [9]. This has been approved by Food and Drug administration and helps in providing secure and sterile water system [30]. Designing and evaluating DUWL is required to solve the problem of biofouling in the pipes. The length of the stagnant section can be reduced by redesigning the units and keep the water flow continuous. Physical cleaning can be done by using sponges or balls, making them pass through the pipeline at high pressure in order to remove the biofilm and destroy biofouling [17].

Chemical approach includes the use of chemical disinfectants which have broad spectrum antimicrobial activity like chlorhexidine gluconate, povidine iodine, glutaraldehyde, ethanol, hypochlorite and peroxide [9]. Besides that, hydrogen peroxide and ozone can be introduced continuously in the DUWL during treatment $[9,29]$, however the efficacy of hydrogen peroxide and ozone regarding purification of DUWL was proven to be limited (9).

6. Sterilization and disinfection - external sterility of dental handpiece can be achieved with autoclaving whereas internal sterility can be achieved by chemiclave [2]. This is because the spores inside the high speed handpieces may survive autoclaving therefore it has to be treated internally with chemical disinfectant [2].

7. Protocols to be followed prior to any dental procedure:-

.1.1. Preprocedural rinses with water [7] and 0.12 to $2 \%$ chlorhexine gluconate or essential oil containing mouthwashes for duration of 60 seconds can cause substantial reduction in bacterial counts [24]. A study by Gupta DG et al demonstrated the efficacy of preprocedural rinsing in chlorhexidine in reducing the aerosol contamination produced by ultrasonic scaling [38].

.1.2. The water line has to be flushed at the start of each clinical day and between patients, for 30 seconds to 1 minute to reduce microbial accumulation due to overnight waterline stagnation [9].

.1.3. High vacuum suction/evacuator which is correctly positioned near the handpiece and close to the mouth can reduce $90 \%$ of aerosol production.

.1.4. Use of rubber dam during conservative procedures [7].

.1.5. At the end of the day, the suction lines should be cleaned with ammonia or enzymatic detergent with water $[9,17]$.

8. Surface contamination can be minimized by the usage of thin plastic bags, wraps or aluminium foils. These barriers can be placed on surfaces like dental unit light handles, electrical and mechanical controls, head and arm rest, dental unit controls and high and slow speed handpiece, ultrasonic scaler, air/water syringe, saliva ejector and HVE hose [24].

9. Periodic evaluation has to be done for a healthy dental environment [24]. Study done by Guida M et al in 2012 highlighted on the need to improve disinfection procedures and air treatment system in dental environment. Microbiological monitoring could represent an important element to detect the presence of risk factors and to adopt control measures [39]. 


\section{Conclusion}

Thus, aerosol contamination can act as a major source of infection to the dental personnel as well as the patient. It is very essential for the dentist to realize that the answer to this risk prevention lies within them. Prevention, taking necessary precautions and following certain protocol prior, during and after the dental procedures are very imperative to avoid the threat of infection spread from the aerosol contamination. However these preventions and precautions taken have to be evaluated and monitored periodically to maintain a healthy dental environment.

\section{References}

[1] Shanti priya Reddy, M.G.S Prasad, Sanjay Kaul, K.Satish, SabanaKakaral, Nirjhar Bhowmik, Efficacy of 0.2\%tempered chlorhexidine as a pre-procedural mouth rinse: a clinical study. J Indian Soc Periodontol, 16(2), 2012 Apr-Jun, 213 - 217.

[2] Sagar Abichandani, Ramesh Nadiger, Cross contamination in dentistry: a comprehensive overview, $J$ of Education and Ethics in Dentistry, 2(1), 2012, 3-9.

[3] zymańska J, Dental bioaerosol as an occupational hazard in a dentist's workplace, Ann Agric Environ Med 2007, 14(2), $203-207$.

[4] Snophia S, M.Manimegalai, Uma S, Sopia, Comparison of efficacy of preprocedural rinsing with chlorhexidine and essential oil mouth in reducing viable bacteria in dental aerosols- a microbiological study, Int J of Contemporary Dentistry, 2(6), 2011 Dec, 16 .

[5] Micik RE, Miller RL, Mazzarella MA, Ryge G, Studies on dental aerobiology: bacterial aerosols generated during dental procedures, J Dent Res, 48(1), 1969, 49-56.

[6] Holbrook WP, Muir KF, Macphee IT, Ross PW, Bacteriological Investigation of the aerosol from ultrasonic scallers, Br Dent J, 144(8), 1978, 245-247.

[7] Maria LC, Anna MS, Marina S, Maurizio D, Gianluca O, Roberto L, Fernanda P, Evaluation of risk of infection through exposure to earosols splatters in dentistry, Am J Infect Control, 36(4), 2008 May, 304-307.

[8] King TB, MuzzinKB, Berry CW, Anders LM, The effectiveness of an aerosol reduction device for ultrasonic scalers., J periodontal, 68(1), 1997 Jan, 45-49.

[9] CarolineL, Pankhurst, NW Johnson, Microbial contamination of dental unit waterlines: the scientific arguments, Int Dent J, 48(4), 1998, 359-368.

[10] Williams JF, Andrews N, Santiago JI, Microbial contamination of dental waterlines: current preventive measures and emerging options, Compend Contin Educ Dent, 17(7), 1996 July, 691-708.

[11] Bentley CD, Burkhart NW, Crawford JJ, Evaluating spatter and aerosol contamination during dental procedures, J Am Dent Assoc, 125(5), 1994, 579-584.

[12] AL Maghloutha, AL Yousef, Y, AL begieh N.Qualitative and quantitative analysis of bacterial aerosols. J of Contemporary Dent Practices.2004;5(4):091-100.

[13] Patricia MM, Alexandrine C, Cristina P, Helder O, Maria CM, Air quality assesmnet during dental practice: Aerosol bacterial counts in an university clinic, Rev Port Estomatol Med Dent Cir Maxilofac, 54(1), 2013, 2-7.

[14] Williams JF, Molinari JA, Andrews N, Microbial contamination of dental unit waterlines: origins and characteristics, Compendium Contin Educ Dent, 17(6), 1996, 612-614.

[15] Tall BD, Williams HN, George KS , Bacterial succession within a biofilm in water supply lines of dental air water syringes, Can $J$ Microbiol, 41(7), 1995, 647-654.

[16] Prospero E, Savini S, Annino I, Microbial aerosol contamination of dental healthcare workers' faces and other surfaces in dental practice, Infect Control Hosp Epidemiol, 24(2), 2003, 139-141.

[17] Liaqat I, A.N. Sabri, "Effect of Biocides on Biofilm Bacteria from Dental Unit Water Lines: Current Microbiology, 56(6), 2008, $619-624$.

[18] Martin M V, The significance of the bacterial contamination of dental unit water systems, Br Dent J, 163(5), $1987,152-154$.

[19] Rautemaa R, Nordberg A, Wuolijoki S K, Meurman JH, Bacterial aerosol in dental practice - a potential hospital infection problem, J of hospital infection, 64(1), 2006, 76-81.

[20] Williams J F, Johnston A M, Johnson B, et al, Microbial contamination of dental unit waterlines: prevalence, intensity and microbial characteristics, JADA, 124(10), 1993, 59-65.

[21] Atlas R M, Williams J F, Huntingdon M K, Legionella contamination of dental unit water, Applied Environ Micro, 61(4), 1995, 1208-1213.

[22] Seetharam KD, Sudheep N. Aerosols: a concern for dentist, Ind J of Dental Advancement, 2(1), 2110, 100-102.

[23] Lucia B, Ioan D, Infection Control in Dentistry -present requirements.OHDMBSC.2(4), 2003

[24] Bhanu M, Deepali B, Infection control and prevention in dentistry, Int J of Dent Advancements, 3(3), 2011, 577-582.

[25] Centers for disease control and prevention-ACIP General Recommendation on Immunization. MMWR (office of Surveillance, Epidemiology, and Laboratory Services, Centers for Disease Control and Prevention (CDC), U.S. Department of Health and Human Services, Atlanta, GA 30333 60(2), 2011, 36)

[26] WilliamG.Kohn, AmyS.Collins, JenniferL.Cleveland, JenniferA.Harte,Kathy J. Eklund, M.H.P, Dolores M. Malvitz, Dr.P.H.Guideline for infection control in dental health care settings. MMWR, 52(17), $2003,37$.

[27] Dutch Working Party on Infection Prevention, Infection Prevention in dental practice (2012).

[28] Murdoch-Kinch C A, Andrews P, Aswan S, et al, Comparison of dental water quality management procedures, JADA, 128(9), $1997,1235-1243$

[29] Exner M, Tuschewitzki G J, Sharnagel J, Influence of biofilms by chemical disinfectants and mechanical cleaning, Zentralbl. Bacteriol Mikrobiol Hyg, 183(5-6), 1987, 549-563.

[30] Williams J F, Andrews N, Santiago J I, Microbial contamination of dental unit waterlines: current preventive measures and emerging options, Compend Contin Educ Dent, 17(7), 1996, 691-708.

[31] Australian Guidelines for the Prevention and Control of Infection in Healthcare. (Commonwealth of Australia. NHMRC, 2010) 94105

[32] CDC. Immunization of Health Care Personnel (Recommendation of the advisory committee on immunization practices (ACIP). MMWR, 2011) 60

[33] Mary J O, Maria A B, Ronnie J R, David CC, Management of dental unit waterline biofilms in the $21^{\text {st }}$ century, Future microbiology, 6(10), 2011, 1209-1226.

[34] Yabune T, Imazato S, Ebiu S, Inhibitory effect in PVDF tube in biofilm formation in DUWL, Dent Mater, 21(8), 2005, 780-786. 
[35] Netajidanesh F, Khosravi, Risk of contamination of different areas of dentist's face during dental practices, Int J Prev Medicine, 4(5), 2013 May, 611-615.

[36] Atlas RM, William JF, Huntinglin MK, Legionella contamination of dental unit waterlines, Appli. Environment microbio, 61(4), 1995, 1208-1213.

[37] Pankhurst CL, Conlters W, philpott-Howard JW, Surman-Lee S. Evaluation of a potential risk of occupational asthma in dentistry exposed to contaminated DUWL, Prim.Dent.Care, 12(2), 2005, 53-59.

[38] Gupta DG, Mirta DD, KP DA, Dupta DA, Comparison of efficacy of pre-procedural mouth rinsing in reducing aerosol contamination produced by ultrasonic scaler: a pilot study, J of Periodontal, 2013 July 15 ( Epub a head of print).

[39] Guida M, Galle, Environmental microbial contamination in dental scaling: a local experiment, Int Prev Med Hyg, 53(4), 2012 Dec, 207-212. 